\title{
PENGARUH KEPEMIMPINAN DAN MOTIVASI TERHADAP PARTISIPASI ANGGOTA DI MASYARAKAT PELESTARI PADI PANDANWANGI CIANJUR (MP3C)
}

\author{
Oleh : \\ Asep Saepul Alam*) \\ Ahmad Nur Rizal *) \\ Dany Rohmatulloh**)
}

\begin{abstract}
Abstrak
Dalam organisasi, pemimpin dan anggota sangat berperan penting untuk menjalankan sebuah organisasi. Sifat kepemimpinan yang dimiliki oleh seorang pemimpin sangat penting untuk mengarahkan anggotanya agar bisa mencapai tujuan organisasi bersama-sama, selain seorang pemimpin, komponen penting dalam organisasi adalah anggota, motivasi yang dimiliki oleh anggota akan berperan pada organisasi untuk tercapainya visi dan misi organisasi. Sehingga kedunya penyebab tersebut akan mempengarhi partisipasi anggota dalam mengikuti kegiatan di dalam organisasi Penelitian ini bertujuan untuk mengetahui pengaruh baik secara simultan ataupun parsial antara kepemimpinan dan motivasi terhadap partisipasi anggota di Masyarakat Pelestari Padi Pandanwangi Cianjur (MP3C). Penelitian ini menggunakan path analisis. Hasil penelitian menunjukan: (1) terdapat pengaruh antara kepemimpinan terhadap partisipasi anggota, (2) terdapat pengaruh antara motivasi terhadap partisipasi anggota, (3) terdapat pengaruh antara kepemimpinan dan motivasi terhadap partisipasi.
\end{abstract}

Kata kunci: Kepemimpinan, Motivasi, Partisipasi

\begin{abstract}
Within the organization, leader and members play an important role in running an organization. The leadership trait possessed by a leader is very important to direct its members to make organizational goals together, In addition to the leader, an important part in the organization is the members, the motivation of the members who will play a role in the organization to make the organization's vision and mission. So both of these causes will affect the participation of members in participating in activities in the organization. This research aims to see the effect both simultaneously and partly between leadership and motivation on member participation of the Masyarakat Pelestari Padi Pandanwangi Cianjur(MP3C). This research uses path analysis. The results showed: (1) there was an influence between leadership on member participation, (2) there was an influence between the motivation of participant participation, (3) there was an influence between leadership and participation of motivation
\end{abstract}

Keywords: Leadership, Motivation, Participation.

*) Dosen Fakultas Sains Terapan UNSUR.

**) Alumni Fakultas Sains Terapan UNSUR. 


\section{PENDAHULUAN}

Indonesia merupakan negara dengan jumlah penduduk terbanyak keempat di dunia, pada tahun 2019, jumlah penduduk di Indonesia mencapai \pm 268 juta orang (BPS, 2020). Dengan jumlah penduduk yang banyak diharapkan dapat menjadi bonus demografi yaitu peluang yang dapat dinikmati sebuah negara karena besarnya proporsi orangorang produktif. Sayangnya walaupun data menunjukan $70 \%$ dari total jumlah penduduk Indonesia merupakan usia angkatan kerja, namun kualitasnya masih rendah (LIPI, 2016). Untuk bisa memanfaatkan jumlah penduduk yang banyak tersebut tentunya harus dimulai dengan peningkatan kualitas sumber daya manusia.

Menurut Ahmaini (2010) dalam Hidayat (2015), organisasi dapat mengubah kehidupan masyarakat, organisasi juga dapat berperan sebagai cagar ilmu pengetahuan. Dengan adanya organisasi tersebut maka masyarakat akan mempunyai tempat untuk berkumpul dan mencapai tujuan bersama, di dalam sebuah organisasi, sumber daya manusia sangat berperan penting diantaranya sebagai pemimpin dan juga anggota. Seorang pemimpin harus bisa mengarahkan anggotanya agar roda organisasi bisa berjalan, dengan begitu tujuan utama dari organisasi akan tercapai Pemimpin merupakan seseorang yang mengarahkan anggotanya dengan menggunakan kepemimpinan dan juga wewenangnya, selain itu untuk mencapai tujuan organisasi, seorang pemimipin harus bertanggung jawab atas pekerjaan anggotanya (Hasibuan, 2011). Kemampuan mempengaruhi atau mengarahkan yang dimiliki seorang pemimpin akan sangat berperan dalam kemajuan sebuah organisasi, karena kemampuan mempengaruhi tersebut dapat membuat anggota menjadi lebih aktif dan berpartisipasi dalam menjalankan kegiatan organisasi. Selain bertugas mengarahkan atau mempengaruhi anggota secara efektif, seorang pemimpin mempunyai tugas untuk membuat perencanaan-perencanaan dan mengawasi agar semua kegiatan yang dijalankan sesuai dengan prosedur yang telah ditetapkan demi tercapainya tujuan bersama, kegagalan sebuah kegiatan atau perencanaan juga akan menjadi tanggungjawab seorang pemimpin.

Diantara tugas-tugas pemimpin ada beberapa tugas yang sangat sentral bagi berjalannya organisasi, yaitu membuat anggota organisasi menjadi aktif dan ikut partisipasi, yaitu keikutsertaan atau pengambilan bagian dalam kegiatan bersama, meliputi pemberian ide atau gagasan dan juga menghadiri kegiatan organisasi (Sumaryadi, 2010). Selain faktor kepemimpinan yang baik seorang anggota juga harus memiliki motivasi atau dorongan dalam berorganisasi, karena akan percuma jika di dalam sebuah organisasi mempunyai pemimpin yang handal, tetapi anggota organisasi tersebut tidak memiliki motivasi dalam berorganisasi.

Masyarakat Pelestari Padi Pandanwangi Cianjur (MP3C), merupakan sebuah lembaga yang dibentuk berdasarkan Peraturan Daerah No.19 Tahun 2012 pasal 3 tentang maksud dari pelestarian Pandanwangi, yaitu pelestarian dan perlindungan padi Pandanwangi Cianjur melalui pembinaan, pengawasan perlindungan dan pengendalian varietas padi Pandanwangi Cianjur guna menjamin ketersediaan produk padi Pandanwangi Cianjur, keberadaan petani Pandanwangi Cianjur, serta keberadaan lahan budidaya padi Pandanwangi Cianjur berkelanjutan.

Mengacu pada Visi MP3C, yaitu mewujudkan beras Pandanwangi Cianjur sebagai beras premium berkualitas prima dan daya saing internasional. Tentunya agar tercapainya visi tersebut harus didasari dengan pondasi organisasi yang kokoh, faktor kepemimpinan, motivasi dan juga partisipasi anggota kelompok akan sangat berpengaruh dalam pelestarian beras pandanwangi, dengan begitu bukan tidak mungkin visi organisasi akan terwujud yaitu "Beras 
Pandanwangi akan menjadi beras premium berkualitas prima dengan daya saing internasional. Dengan kuatnya pondasi organsasi maka akan lebih mudah untuk mengembangkan organisasi dan memecahkan permasalahan yang datang dari luar organisasi.

Dengan demikian peran kepemimpinan ketua dan motivasi anggota itu sendiri akan berpengaruh terhadap partisipasi anggota pada lembaga Masyarakat Pelestari Padi Pandanwangi Cianjur (MP3C). Dengan indikator partisipasi seperti, keaktifan dalam memberikan ide gagasan ataupun saran dan aktif dalam mengikuti berbagai kegiatan-kegiatan yang diadakan organisasi. Sehingga tujuan dibentuknya MP3C sebagai Pelestarian dan perlindungan terhadap pandanwangi dapat terwujud dengan begitu pandanwangi dapat bersaing dengan beras yang mempunya SIG lainnya.

Selelah melihat pentingnya kepemimpinan, motivasi dan juga partisipasi anggota. Peneliti tertarik untuk mengidentifikasi lebih dalam terkait ketiga faktor-faktor tersebut dengan judul "Pengaruh Kepemimpinan Dan Motivasi Terhadap Partisipasi Anggota Di Masyarakat Pelestari Padi Pandanwangi Cianjur (MP3C)". adalah:

Tujuan dilakukannya penelitian ini

1. Mengetahui pengaruh kepemimpinan terhadap partisipasi anggota kelompok MP3C.

2. Mengetahui pengaruh motivasi terhadap partisipasi anggota kelompok MP3C.

3. Mengetahui pengaruh secara simultan kepemimpinan dan motivasi terhadap partisipasi anggota kelompok MP3C.

\section{METODE PENELITIAN}

\section{Waktu dan Tempat}

Penelitian ini dilaksanakan pada bulan Januari sampai September 2020, Tempat dilaksanakannya penelitian ini di sekretariat Masyarakat Pelestari Padi Pandanwangi Cianjur (MP3C), yang beralamat di Jl. Raya Bandung No 61, Bojong, Kecamatan Karangtengah, Kabupaten Cianjur, Jawa Barat

\section{Jenis dan Sumber Data}

Jenis data dan sumber data yang digunakan dalam penelitian ini yaitu, data primer dan data sekunder. data primer pada penelitian ini didapatkan dari metode observasi, kuesioner/angket, dan wawancara secara langsung dengan pengurus ataupun anggota MP3C. Sedangkan data sekunder yang dipergunakan pada penelitian ini didapatkan dari jurnal-jurnal atau pun buku yang relevan dengan penelitian.

\section{Operasional Variabel}

Dalam penelitian ini variabel dibedakan menjadi dua variabel yaitu :

1. Variable exogenous, merupakan variabel yang tidak terdapat penyebab eksplisitnya dan dalam diagram model jalur tidak ada anak panah yang mengarah padanya, variabel ini berfungsi sebagai variabel bebas (Sarwono, 2012). Variabel exogenous dalam penelitian ini adalah kepemimpinan dan motivasi.

2. Variabel endogenous, merupakan variabel yang mempunyai anak panah yang mengarah kepadanya, termasuk semua variabel perantara atau variabel terikat (Sarwono, 2012). Dalam penelitian ini variabel endogenous yang digunakan adalah partisipasi.

Rincian operasional variabel dalam penelitian ini dapat dilihat pada tabel 1 . 
Tabel 1. Operasional Variabel.

\begin{tabular}{|c|c|c|c|}
\hline Variabel & Konsep Variabel & Indikator & Skala \\
\hline $\begin{array}{l}\text { Kepemimpinan } \\
\text { (X1) }\end{array}$ & $\begin{array}{l}\text { Kepemimpinan adalah } \\
\text { mempengaruhi orang-orang agar mereka } \\
\text { ingin bekerjasama untuk mencapai tujuan } \\
\text { yang diinginkan (Kartono, 2010). }\end{array}$ & $\begin{array}{l}\text { - Pembimbing } \\
\text { - Komunikatif } \\
\text { - Demokrasi }\end{array}$ & Ordinal \\
\hline Motivasi (X2) & $\begin{array}{l}\text { Motivasi yaitu sikap-sikap atau nilai-nilai } \\
\text { yang mempengaruhi seseorang dalam } \\
\text { mencapai sesuatu sesuai dengan tujuan yang } \\
\text { didasari dari dalam dirinya dan bukan } \\
\text { pengaruh pihak lain (McClelland dalam Rivai } \\
\text { dan Sagala, 2011). }\end{array}$ & $\begin{array}{l}\text { - Kebutuhan } \\
\text { berprestasi. } \\
\text { - Kebutuhan } \\
\text { berafiliasi. } \\
\text { - Kebutuhan } \\
\text { kekuatan }\end{array}$ & Ordinal \\
\hline Partisipasi (Y) & $\begin{array}{l}\text { Partisipasi adalah keikutsertaan seseorang } \\
\text { dalam sebuah kegiatan yang diadakan pihak } \\
\text { lain seperti kelompok, asosiasi dan } \\
\text { organisasi-organisasi pemerintah, dimana } \\
\text { keikutsertaannya dalam bentuk pencurahan } \\
\text { tenaga, pikiran dan material (Rusida, 1990) }\end{array}$ & $\begin{array}{l}\text { - Mengikuti kegiatan- } \\
\text { kegiatan. } \\
\text { - Aktif memberikan } \\
\text { ide. } \\
\text { - Memberikan saran } \\
\text { dan kritik. }\end{array}$ & Ordinal \\
\hline
\end{tabular}

\section{Populasi dan Sampel}

Populasi dalam penelitian ini adalah seluruh anggota Masyarakat Pelestari Padi Pandanwangi Cianjur (MP3C) yang berjumlah 320 orang. Sampel yang akan digunakan pada penelitian ini sebanyak 76 orang yang terdiri dari anggota MP3C, angka tersebut didapat dari perhitungan sebagai berikut dengan menggunakan rumus slovin :

$$
\begin{gathered}
\mathrm{n}=\frac{\mathrm{N}}{1+\left(\mathrm{N} \mathrm{x} \mathrm{e}^{2}\right)} \\
\mathrm{n}=\frac{320}{1+\left(320 \mathrm{x} 0.1^{2}\right)} \\
\mathrm{n}=\frac{320}{4.2}
\end{gathered}
$$

Kesalahan

$\mathrm{n}=76$

Keterangan:

$\mathrm{n}$ : Ukuran sampel

$\mathrm{N}$ : Populasi

$\mathrm{e}^{2}$ : Persentasi

\section{Metode Analisis \\ Uji Validitas}

Uji validitas digunakan untuk mengukur sah atau valid tidaknya suatu kuesioner. Suatu kuesioner dikatakan valid jika pertanyaan pada kuesioner mampu mengungkapkan sesuatu yang akan diukur oleh kuesioner tersebut (Ghozali, 2011). jika nilai $r$ hitung $>$ dari $r$ tabel maka dapat dikatakan bahwa instrument penelitian valid (Sujarweni, 2015).

\section{Uji Reliabilitas}

Menurut Riyanto (2011), Reabilitas merupakan kestabilan dalam pengukuran dan jika digunakan berulang-ulang nilainya akan tetap sama. Sebuah variabel dapat dinyatakan reliabel jika memberikan nilai Cronbach Alpha > 0,6 (Ghozali, 2011).

\section{Uji T}

Uji $t$ adalah pengujian untuk mengetahui seberapa jauh pengaruh variabel exogenous terhadap variabel endogenous secara individu. Jika nilai $\mathrm{t}$ hitung $>\mathrm{t}$ tabel atau nilai signifikansi $<$ 0,05, maka dapat dikatakan bahwa variabel exogenous berpengaruh terhadap variabel endogenous (Ghozali, 2011).

\section{Uji F}

Uji F merupakan sebuah pengujian apakah semua variabel exogenous yang diteliti mempunyai pengaruh secara bersama-sama terhadap variabel endogenous. Jika nilai $\mathrm{t}$ hitung $>\mathrm{t}$ tabel atau nilai signifikansi $<0,05$, maka dapat dikatakan bahwa variabel exogenous berpengaruh secara simultan terhadap variabel endogenous (Ghozali, 2011). 


\section{Koefisien Determinasi (R2)}

Koefisien determinasi (R2) adalah alat untuk mengukur seberapa jauh kemampuan model dalam menerangkan sebuah variasi variabel endogenous Ghozali (2011).

\section{Path Analysis}

Menurut Sarwono (2012) Path analysis merupakan teknik yang menganalisis hubungan sebab akibat yang inheren antar variabel yang disusun berdasarkan urutan dengan menggunakan koefisien jalur untuk menentukan besarnya pengaruh variabel exogenous terhadap variabel endogenous. Diagram jalur dalam penelitian ini adalah terdapat pada gambar 1 di bawah:

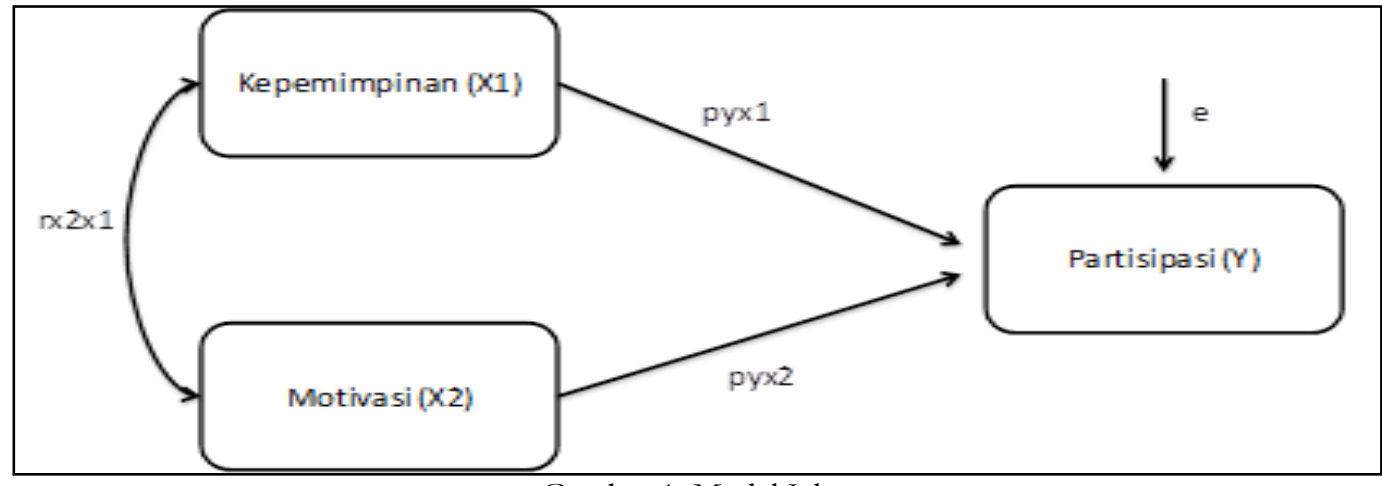

Gambar 1. Model Jalur.

Berdasarkan diagram model jalur, diketahui bahwa hanya terdapat satu persamaan struktural, yaitu sebagai berikut:

$$
\mathrm{Y}=\mathrm{PYX} 1+\mathrm{PYX} 2+\mathrm{e}
$$

Keterangan :

$$
\begin{array}{ll}
\mathrm{Y} & =\text { Partisipasi } \\
\mathrm{P} & =\text { Koefisien Jalur } \\
\mathrm{X} 1 & =\text { Kepemimpinan } \\
\mathrm{X} 2 & =\text { Motivasi } \\
\mathrm{e} & =\text { Error }
\end{array}
$$

\section{HASIL DAN PEMBAHASAN}

\section{Gambaran Umum Tempat Penelitian}

MP3C merupakan organisasi yang berdiri pada tanggal 25 Juni 2014, sebuah organisasi yang mempunyai kepedulian terhadap pengembangan dan pelestarian beras dan padi pandanwangi. Latar belakang didirikannya MP3C adalah untuk melestarikan, memelihara dan mengembangkan Padi Pandanwangi, sehingga terhindar dari kepunahan. MP3C adalah organisasi yang mewadahi bagi pengusaha petani, pengolah, konsumen, akademisi, pemerintah, pemerhati dan lembaga/koperasi/organisasi padi dan beras pandanwangi. Kantor sekretariat MP3C beralamat di Jalan Raya Bandung, No. 61, Cianjur.

\section{Karakteristik Responden}

1. Jenis Kelamin

Berdasarkan gambar 2. Dapat dilihat bahwa 90\% atau 63 orang responden berjenis kelamin laki-laki dan $10 \%$ atau 7 orang berjenis kelamin perempuan, artinya mayoritas reponden anggota MP3C yang merupakan petani, produsen dan akademisi yang umumnya banyak diisi oleh laki-laki. 


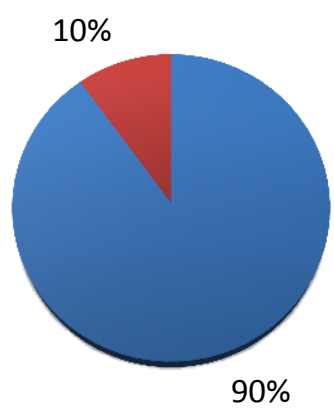

- Laki-laki

Perempuan

Gambar 2. Karakteristik Jenis Kelamin Responden.

2. Usia

Berdasarkan gambar 3. Dapat dilihat bahwa $66 \%$ atau 46 orang responden berumur lebih dari 50 tahun, $2 \%$ atau seorang berumur kurang dari 20 tahun, 4\% atau 3 orang berumur 20-30 tahun, $7 \%$ atau 5 orang berumur 31-40, $21 \%$ atau 15 orang berumur $41-50$ tahun.Artinya mayoritas responden berusia lebih dari 50 tahun.

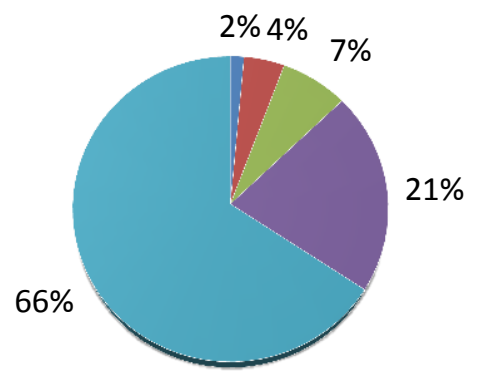

$$
\begin{aligned}
& -<20 \\
& -20-30 \\
& -31-40 \\
& -41-50 \\
& ->50
\end{aligned}
$$

Gambar 3. Karakteristik Usia Responden

3.Pendidikan

Berdasarkan gambar 4. Dapat dilihat bahwa $73 \%$ atau 51 orang berpendidikan terakhir SD, 3\% atau 2 orang berpendidikan terakhir SMP, 9\% atau 6 orang berpendidikan terakhir SMA, $7 \%$ atau 5 orang berpendidikan terakhir Sarjana, $8 \%$ atau 6 orang tidak bersekolah atau tidak lulus SD.

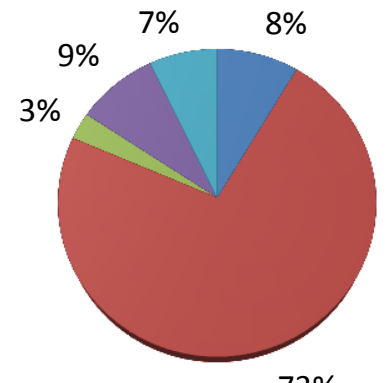

Tidak lulus SD

$\square \mathrm{SD}$

$\square$ SLTP/SMP

SLTA/SMA

$\square$ Sarjana

Gambar 4. Karakteristik Pendidikan Responden.

\section{Keanggotaan}

Berdasarkan gambar 5. Dapat dilihat bahwa 90\% atau 63 responden merupakan petani, $3 \%$ atau 2 orang merupakan pengolah, $7 \%$ atau 5 responden merupakan akademisi, dan tidak terdapat responden dari dinas, pemasar dan pemerhati. 


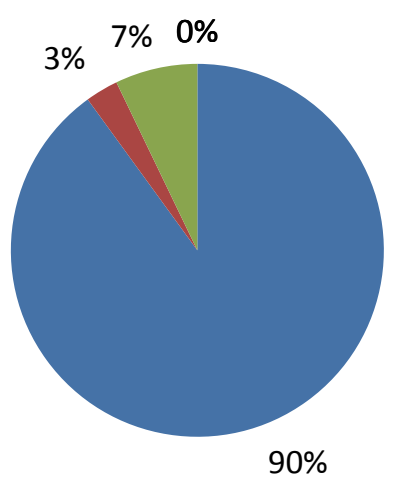

- Petani

Pengolah

Akademisi

- Pemasaran

Dinas

Pemerhati

Gambar 5. Karakteristik Keanggotaan Responden.

\section{Uji Validitas}

Hasil uji validitas variabel kepemimpinan, motivasi dan partisipasi dapat dilihat pada tabel-tabel di bawah.

Tabel 2. Uji Validitas Kepemimpinan.

\begin{tabular}{cccc}
\hline No Item & R-Hitung & R-Tabel & Keterangan \\
\hline 1 & 0.643 & 0.235 & VALID \\
2 & 0.494 & 0.235 & VALID \\
3 & 0.652 & 0.235 & VALID \\
4 & 0.745 & 0.235 & VALID \\
5 & 0.714 & 0.235 & VALID \\
\hline
\end{tabular}

Sumber : Data Primer Diolah, 2020.

Tabel 3. Uji Validitas Motivasi.

\begin{tabular}{cccc}
\hline No Item & R-Hitung & R-Tabel & Keterangan \\
\hline 1 & 0.576 & 0.235 & VALID \\
2 & 0.546 & 0.235 & VALID \\
3 & 0.830 & 0.235 & VALID \\
4 & 0.729 & 0.235 & VALID \\
5 & 0.709 & 0.235 & VALID \\
6 & 0.630 & 0.235 & VALID \\
\hline
\end{tabular}

Sumber : Data Primer Diolah, 2020.

Tabel 4. Uji Validitas Partisipasi

\begin{tabular}{cccc}
\hline No Item & R-Hitung & R-Tabel & Keterangan \\
\hline 1 & 0.652 & 0.235 & VALID \\
2 & 0.717 & 0.235 & VALID \\
3 & 0.657 & 0.235 & VALID \\
4 & 0.767 & 0.235 & VALID \\
\hline
\end{tabular}

Sumber : Data Primer Diolah, 2020.

Berdasarkan ketiga tabel di atas dapat dilihat bahwa nilai R-Hitung $>$ RTabel, Sehingga semua item pada ketiga variabel dapat dikatakan valid.

\section{Uji Reliabilitas}

Uji reliabel ketiga variabel dapat dilihat pada tabel 5 di bawah. 
Tabel 5. Uji Reliabilitas

\begin{tabular}{lccc}
\hline \multicolumn{1}{c}{ Variabel } & Cronbach Alpha & Cutoff & Keterangan \\
\hline Kepemimpinan & 0.653 & 0.6 & Reliabel \\
Motivasi & 0.757 & 0.6 & Reliabel \\
Partisipasi & 0.647 & 0.6 & Reliabel \\
\hline
\end{tabular}

Sumber : Data Primer Diolah, 2020.

Berdasarkan tabel di atas dapat dilihat bahwa nilai Cronbach Alpha ketiga variabel bernilai lebih besar dari nilai sehingga semua variabel reliabel

\section{Uji T}

Uji $t$ bertujuan untuk menguji apakah variabel kepemimpinan dan motivasi berpengaruh terhadap variabel partisipasi secara parsial. Kriteria pengukuran uji $t$ adalah jika nilai signifikansi $<0.05$ atau $t_{\text {hitung }}>t_{\text {tabel }}$ maka terdapat pengaruh antara variabel bebas terhadap variabel terikat. Nilai t hitung dapat dilihat pada tabel 6 .

Tabel 6. Coefficients Uji T.

\begin{tabular}{|c|c|c|c|c|c|}
\hline \multirow{3}{*}{ Model } & \multicolumn{3}{|c|}{ Coefficients $^{\mathrm{a}}$} & \multirow[b]{3}{*}{$\mathbf{t}$} & \multirow[b]{3}{*}{ Sig. } \\
\hline & \multicolumn{2}{|c|}{$\begin{array}{l}\text { Unstandardized } \\
\text { Coefficients }\end{array}$} & \multirow{2}{*}{$\begin{array}{c}\text { Standardized } \\
\text { Coefficients } \\
\text { Beta }\end{array}$} & & \\
\hline & $\mathbf{B}$ & Std. Error & & & \\
\hline $1 \quad$ (Constant) & 2.696 & 1.568 & & 1.72 & 0.09 \\
\hline Kepemimpinan & 0.437 & 0.088 & 0.521 & 4.964 & 0.000 \\
\hline Motivasi & 0.187 & 0.066 & 0.299 & 2.852 & 0.006 \\
\hline
\end{tabular}

a. Dependent Variable: Partisipasi.

Sumber : Data Primer Diolah, 2020.

Sedangkan nilai t tabel didapat dari perhitungan : $\mathrm{t}_{\text {tabel }}=\alpha / 2: \mathrm{n}-\mathrm{k}-1$

$$
\begin{aligned}
& =0.05 / 2: 70-2-1 \\
& =0.025: 67 \\
& =1.996
\end{aligned}
$$

Keterangan:

$\alpha=$ Tingkat kepercayaan $/$ koefisien

$\mathrm{n}=$ Jumlah sampel

$\mathrm{k}=$ Jumlah variabel bebas

Sehingga uji hipotesis untuk uji parsial adalah sebagai berikut

1. Untuk variabel kepemimpinan pengujian uji $\mathrm{t}$ adalah $4.964>1.996$ dan nilai signifikan $0.000<0.05$. Artinya terdapat pengaruh antara variabel kepemimpinan terhadap partisipasi. Sehingga HI diterima dan H0 ditolak.

2. Untuk variabel motivasi hasil pengujian uji $\mathrm{t}$ adalah $2.852>1.996$ dan nilai signifikansi $0.006<0.05$. Artinya terdapat pengaruh antara variabel motivasi terhadap variabel partisipasi. Sehingga HI diterima dan HO ditolak

Uji F

Uji F merupakan pengujian untuk mengetahui apakah terdapat pengaruh antara variabel bebas secara bersama-sama atau simultan terhadap variabel terikat. Dapat dikatakan berpengaruh apabila nilai $F_{\text {hitung }}>F_{\text {tabel }}$ atau nilai signifikan $<0.05$. Nilai F tabel didapat dari perhitungan : $\mathrm{F}_{\text {tabel }}=\mathrm{k}: \mathrm{n}-\mathrm{k}$

$$
\begin{aligned}
& =2: 70-2 \\
& =2: 68 \\
& =3.13
\end{aligned}
$$

Keterangan :

$\mathrm{k}=$ Jumlah variabel bebas

$\mathrm{n}=$ Sampel penelitian

Sedangkan nilai $F$ tabel dapat dilihat pada tabel 7 . 
Tabel 7. Anova Uji F.

\begin{tabular}{|c|c|c|c|c|c|}
\hline \multicolumn{6}{|c|}{ ANOVA $^{\mathbf{b}}$} \\
\hline Model & Sum of Squares & Df & Mean Square & $\mathbf{F}$ & Sig. \\
\hline 1 Regression & 65.580 & 2 & 32.790 & 42.326 & $0.000^{\mathrm{a}}$ \\
\hline Residual & 51.905 & 67 & 0.775 & & \\
\hline Total & 117.486 & 69 & & & \\
\hline
\end{tabular}

a. Predictors: (Constant), Motivasi, Kepemimpinan

b. Dependent Variable: Partisipasi

Sumber : Data Primer Diolah, 2020.

Berdasarkan hasil tersebut diketahui bahwa $42.326>3.13$ dan nilai signifikansi $0.000<0.05$, yang berarti bahwa variabel kepemimpinan dan variabel motivasi berpengaruh secara bersama-sama terhadap variabel partisipasi. Sehingga HI diterima dan $\mathrm{H} 0$ ditolak.

\section{Koefisien Determinasi $\left(\mathrm{R}^{2}\right)$}

Analisis koefisien determinasi dilakukan untuk mengetahui berapa persentase kemampuan variabel Kepemimpinan dan movitasi dalam mempengaruhi variabel Partisipasi. $\mathrm{R}^{2}$ bernilai antara 0 sampai 1 . Nilai $\mathrm{R}^{2}$ pada penelitian ini dapat dilihat pada tabel di 8 .

Tabel 8. Model Summary R².

\begin{tabular}{ccrrr}
\hline \multicolumn{5}{c}{ Model Summary $^{\mathrm{b}}$} \\
\hline Model & $\mathbf{R}$ & \multicolumn{1}{c}{ R Square } & Adjusted R Square & Std. Error of the Estimate \\
\hline 1 & $0.747^{\mathrm{a}}$ & 0.558 & 0.545 & 0.880 \\
\hline
\end{tabular}

a. Predictors: (Constant), Motivasi, Kepemimpinan

b. Dependent Variable: Partisipasi

Sumber : Data Primer Diolah, 2020.

Berdasarkan tabel di atas dapat dilihat bahwa nilai $\mathrm{R}^{2}$ adalah 0.558 . Hal ini berarti bahwa kepemimpinan dan motivasi berpengaruh secara simultan terhadap partisipasi sebesar 55,8\%.

\section{Path Analysis}

Untuk mengetahui model jalur antara pengaruh variabel kepemimpinan dan motivasi terhadap variabel partisipasi diperoleh dari tabel 6 di atas.

Berdasarkan nilai Standardized Coefficients Beta diperoleh diagram model jalur sebagai berikut :

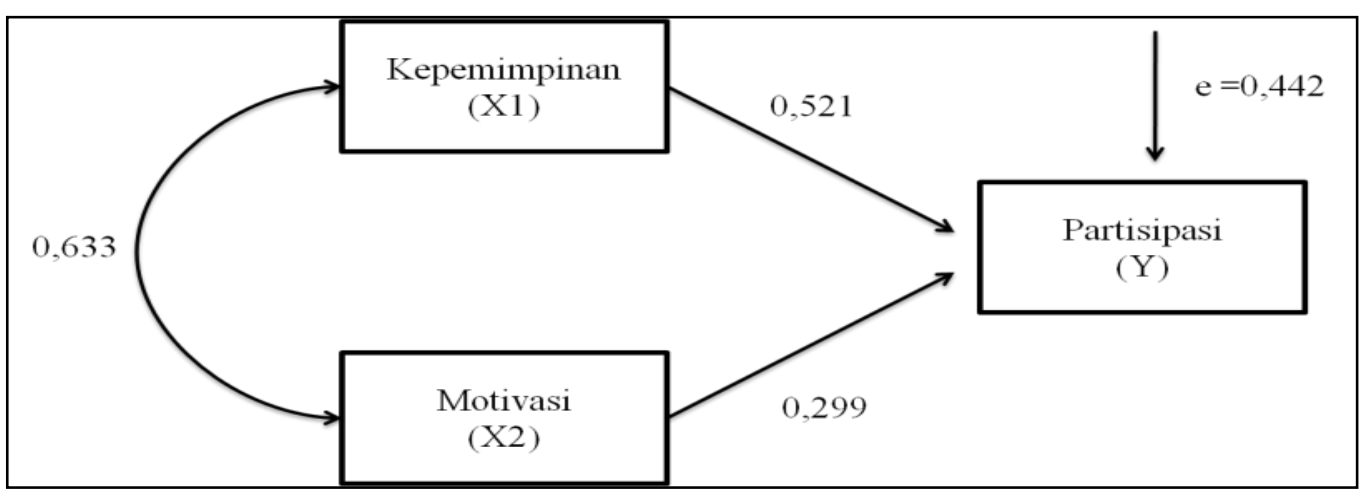

Gambar 6. Model Jalur.

Berdasarkan model jalur tersebut, nilai korelasi antara kepemimpinan dan motivasi sebesar 0,633 artinya terdapat hubungan yang kuat dan searah antara kepemimpinan dan motivasi sehingga apabila kepemimpinan dinilai tinggi atau mengalami kenaikan maka motivasi juga akan dinilai tinggi dan juga mengalami 
kenaikan yang sama. Dari model jalur tersebut, maka diperoleh persamaan struktural sebagai berikut :

Partisipasi $=0,521$ Kepemimpinan + 0,299 Motivasi + e

Berdasarkan diagram jalur dan persamaan struktural tersebut maka dapat disimpulkan bahwa pengaruh antara kepemimpinan terhadap partisipasi adalah 0,521 atau sebesar 52,1\%, dan pengaruh antara motivasi terhadap partisipasi adalah 0,299 atau sebesar 29,9\%, sedangkan pengaruh secara simultan antara kepemimpinan dan motivasi terhadap partisipasi dapat dilihat berdasarkan tabel 4.25 Hasil Koefisien Determinasi pada kolom $R$ square bernilai 0,558 atau sebesar $55,8 \%$, Berdasarkan nilai tersebut dapat diperoleh nilai e dengan mengunakan perhitungan di bawah:

$$
\begin{aligned}
& e=1-R^{2} \\
& e=1-0,558 \\
& e=0,442
\end{aligned}
$$

\section{KESIMPULAN}

Berdasarkan hasil dan pembahasan pada bab sebelumnya, maka diperoleh kesimpulan sebagai berikut :

1. Terdapat pengaruh positif dan signifikan antara kepemimpinan ketua kelompok terhadap partisipasi anggota di Masyarakat Pelestari Padi Pandanwangi Cianjur (MP3C). Artinya jika semakin baik kepemimpinan ketua MP3C maka akan semakin meningkatkan partisipasi anggota MP3C.

2. Terdapat pengaruh positif dan signifikan antara motivasi terhadap partisipasi anggota di MP3C. Artinya jika motivasi dalam diri anggota meningkat maka akan meningkatkan partisipasi anggota MP3C

3. Terdapat pengaruh secara simultan atau bersama-sama antara kepemimpinan dan motivasi terhadap partisipasi anggota di MP3C. Pengaruh yang dihasilkan kepemimpinan dan motivasi secara simultan adalah sebesar $55,8 \%$. Dan sisanya dipengaruhi oleh variabel lain.

\section{DAFTAR PUSTAKA}

Badan Pusat Statistika. 2020. Indonesia dalam Angka 2019.

Ghozali Imam. 2011. Aplikasi analisis multivariate dengan program IBM SPSS. Universitas Diponegoro. Semarang.

Hasibuan Malayu. 2011. Manajemen Sumber daya Manusia. Bumi Aksara. Jakarta.

Hidayat Taufik. 2015. Faktor-Faktor yang Mempengaruhi Keikutsertaan

Berorganisasi Mahasiswa FIKES UMP. Skripsi. Program Studi Ilmu Keperawatan Fakultas Ilmu Kesehatan. Universitas Muhammadiyah Purwokerto.

Kartono Kartini, 2009. Pemimpin dan Kepemimpinan. Rajawali Pers. Jakarta.

Peraturan Daerah Kabupaten Cianjur Nomor 19 Tahun 2012. Cianjur

Riyanto Agus. 2011. Buku ajar metodologi penelitian. EGC. Jakarta.

Rusidi. 1990. Dinamika Kelompok Tani. Fakultas Pertanian. UNPAD

Sarwono Jonathan. 2012. Path Analysis Teori, Aplikasi, Prosedur Analisis untuk Riset Skripsi, Tesis dan Disertasi (Menggunakan SPSS). PT Elex Media Komputindo Kompas Gramedia. Jakarta

Sujarweni Wiratna. 2015. Metodologi Penelitian Bisnis dan Ekonomi, Pustakabarupres. Yogyakarta.

Sumaryadi I Nyoman. 2010. Sosiologi pemerintaban. Ghalia Indonesia. Bogor.

BVeithzal Rivai dan Sagala Ella Jauvani 2011. Manajemen Sumber Daya Manusia untuk Perusabaan. Raja Grafindo Persada. Jakarta. 